\section{Lateral Luxation of Incisor - A Case Report of Using a New Cone- Beam Computed Tomography Software and Reposition Guideline}

Priscilla Barbosa Ferreira Soares ${ }^{1} \mathbb{D}$, Andomar Bruno Fernandes Vilela ${ }^{2}$,

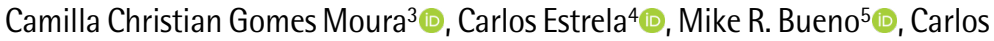
José Soares ${ }^{2}$ (D)

Lateral luxation injuries are one of the most severe periodontal injuries in dental trauma. The correct diagnosis followed by repositioning of the tooth on the right position is fundamental for the periodontal ligament healing. This study reported a clinical case of lateral luxation of maxillary central incisor involving a new cone beam computed tomography (CBCT) software for reconstruction (e-Vol DX) to confirm the lateral luxation after no conclusive dental trauma injury definition by using conventional exam. The lateral luxation injury was digitally reduced by insertion of tooth back to its alveolus, and at the same session, the tooth was stabilized with a rigid splint and further changed to a semirigid nylon splint. During the pulpal status monitoring, the pulp was diagnosed necrotic, then the root canal was treated to prevent root resorption. External office-bleaching and restorative procedure was performed. The 4-years follow up and new imaging exam and digital reconstruction confirmed bone healing and no complication. CBCT images analyzed by eVol DX can be used to determine and to guide lateral luxation treatment.
'Department of Periodontology and Implantology, School of Dentistry, UFU - Universidade Federal de Uberlândia, MG, Brazil ${ }^{2}$ Department of Operative Dentistry and Dental Materials, Dental School, UFU - Universidade Federal de Uberlândia, MG, Brazil ${ }^{3}$ Department of Endodontics, Dental School, UFU - Universidade Federal de Uberlândia, MG, Brazil ${ }^{4}$ Department of Stomatologic Sciences, UFG - Universidade Federal de Goiás, Goiânia, G0, Brazil ${ }^{5} \mathrm{CRIOF}$ - Radiological Center of Orofacial Images, Cuiabá, MT, Brazil

Correspondence: Dr. Carlos José Soares, Avenida Pará, 1720, Bloco 4L, Anexo A, Sala 42, 38400-902 Uberlândia, MG, Brasil. Tel: +55-34-9997-13472. e-mail: carlosjsoares@ufu.br

Key Words: lateral luxation; conebeam tomography; guideline; splinting; tomography software.

\section{Introduction}

Lateral luxations of anterior teeth are one of the most severe types of dental injuries (1). This traumatic dental injury is characterized by the buccal-lingual displacement of the tooth with involvement of alveolar bone fracture (2). The imprisonment of the root apex into the alveolar bone fracture results on tooth immobility and ankylosis percussion sound (3). Due to the rupture of the blood supply, the pulp necrosis is common on permanent teeth with closed apex involved in the lateral luxation injury (4). The most frequent periodontal complications involve the external root resorption, marginal bone loss and ankylosis, mainly in delayed or incorrect repositioning $(4,5)$

The diagnosis of lateral luxation involves clinical, radiograph or cone-beam computer tomography (CBCT) exams, (6) however, due to the two-dimensional image of the radiography, the diagnosis of the lateral luxation injury is not easy. The CBCT, when available, is a better option to help the clinician for the lateral luxation definition (7). Moreover, CBCT imaging meets the recommendations of the American Association of Endodontics for the effective resolution of complex clinical conditions (8).

Current guidelines recommends the repositioning of the tooth to the original position using digital pressure and the stabilization for a minimum period of four weeks in order to favor periodontal ligament repair (5). Endodontic intervention is also essential, especially in closed-apex teeth, in an attempt to prevent root resorptions (7). Proper visualization of the apical position after lateral luxation is indispensable before, during, and after treatment because the success depends on accurate diagnosis, planning, and execution. The 3D reconstruction by using specific software may contribute substantially with the treatment. (9). Recently, Estrela et al. (9) demonstrated novel software (e-Vol DX; CDT Software, Bauru, SP, Brazil) is an important tool for endodontic treatment. However, no study has demonstrated its utility in the diagnosis, planning, execution, and follow-up phases of lateral luxation dental trauma. Therefore, this study discussed a clinical case of dental trauma involving undiagnosed lateral luxation of a maxillary central incisor initially attended at private office, which was referred to a Public Dental Trauma Service where was used a new CBCT software (e-Vol DX) for diagnosis, planning and follow-up of the lateral luxation injury.

\section{Case Report}

An 11 year-old patient was referred to the Dentoalveolar Trauma Clinic at Federal University of Uberlândia, MG, Brazil for examination after dentoalveolar trauma involving maxillary left permanent central incisor. Patient's parents reported that he had fainted after a blood test, bumping his mouth against the floor approximately $24 \mathrm{~h}$ before. The patient received the first care at a private dental office, when a periapical radiograph was taken. However, 
no treatment was performed since the affected teeth had no increased mobility and the bleeding from the gingival sulcus had already ceased. The patient reported to receive at first clinical session, the instruction to eat pasty or liquid foods for 15 days and to take painkillers and non-steroidal anti-inflammatories if necessary. However, the patient's parents decided to come to the Dental Trauma Service of the Federal University of Uberlândia since he reported having difficult to eat because the left central incisor was in premature occlusal contacting to the antagonist incisor, generating pain and discomfort during biting.

The patient was examined and clinical inspection showed that the incisal edges of both central incisors was misaligned. The gingiva around the traumatized tooth was swollen and reddish (Fig. 1A). From a palatal and lateral view, it was observed that the crown of left central incisor was displaced to the palatal direction (Fig. 1B,C). During the excursive mandibular movements, the left central incisor prematurely contacted the antagonist incisor. The palpation exam of the oral vestibule revealed an alveolar protuberance, which is an important indicative that the root could be forced and fractured the alveolar process, resulting in immobility due the root apex trapped on bone

presented a "metallic" sound. Image examination is important to determine concomitant injuries, as root fractures to the tooth or even on adjacent teeth, and moreover, these exams are important to determine the repositioning technique. As displacement of lateral luxation injuries frequently occurs to buccal or palatal direction, intra-oral $2 \mathrm{D}$ radiographs may not reveal the severity of the injury in the sagittal plane (6). In this particular case report, the images of the periapical radiographs were not conclusive regarding the type of injury, therefore CBCT was indicated for diagnosis of dental trauma type. The patient was imaged using cone-beam computed tomographic scanning (i-CAT GXCB-500; Imaging Sciences International, Hatfield, PA, USA), and following standard protocol was used with Voxel dimensions were $0.125 \mathrm{~mm}$. A total of 704 slices were obtained with $23 \mathrm{~s}$ of acquisition and exposure parameters of $120 \mathrm{kV}$ and $3.0-7.0 \mathrm{~mA}$. The DICOM files were exported and reconstructed three-dimensionally by using a novel CBCT software (e-Vol DX, CDT Software, Bauru, SP, Brazil) (12). CBCT was obtained and the software reconstruction indicated and confirmed the fracture of the alveolar process and the lateral root displacement with the apex trapped outside the alveolus, characterizing the lateral luxation (Fig.1D and Fig. 2A-D).

After the anesthesia, the root apex of left central incisor was moved digitally towards the incisal direction, allowing the tooth being gently extruded to unlock itself from the alveolar bone (10). During this procedure it is extremely important to hold the tooth by the incisal and palatal side of the crown. The pushing force should be concentrated at the apex and directed downwards and inwards at same time. The tooth was correctly repositioned into the socket and the bone was gently set into the socket as shown in the schematic guideline (Fig. 3A,B). It is important to report that the typical sound is observed when the tooth is correctly inserted into the alveolus bone. The ringing sound of the tooth with slight movement of the blood vessel. Periapical $x$-ray was taken from a mesial angle to confirm that tooth's ideal position was reestablished and a stainless rigid orthodontic splint was made (Fig. 3C) (11).

The patient was re-evaluated after 1 week. The traumatized tooth was asymptomatic and responded positively to the pulp vitality tests. No discomfort was reported and the adjacent teeth had no signs of abnormality. After 15 days, the response continued positive to pulp vitality tests. The rigid splint was replaced by a semi-rigid nylon-composite resin splint, which was maintained for 2 weeks (Fig. 3D). After this period, the semi-rigid splint was removed, pulp vitality test yielded a negative response. Furthermore, an incipient apical alteration was detected and coronal tooth color change was observed. Therefore, endodontic treatment was indicated. The endodontic access was gained and instrumentation was carefully performed due to the wide root canal. Concomitantly to the instrumentation, the root canal was irrigated at each instrument change with $2 \mathrm{~mL}$ of $2.5 \%$ sodium hypochlorite. Calcium hydroxide medication (Ultracal, Ultradent Products, Inc., South Jordan, UT, USA) was inserted into the root canal and the tooth was temporarily sealed with conventional glass-ionomer cement (Maxxion R, FGM, Joinville, SS, Brazil). The root canal was filled with a gutta-percha cone compatible with a hand file size 60 and AHPlus endodontic sealer (Dentsply, York, PA, USA) using warm vertical condensation and the endodontic access was filled with composite resin Filtek Z350 XT (3M ESPE, St. Paul, MN, USA).

After 30 days, the patient was examined and no apical alteration was observed. The tooth presented normal mobility. The detected tooth crown color alteration was treated by the external bleaching technique using 35\% Hydrogen Peroxide (Whiteness HP Maxx, FGM, Joinville, Santa Catarina, Brazil) with three applications of the bleaching material for 15 min each application, as manufacturer recommendation. A single session was enough to match color with adjacent teeth. Thirty days later, another CBCT exam and software reconstruction was made, which confirmed the buccal alveolar process healing at tooth apex (Fig. 4A-B). After 4 years of follow-up, clinical 


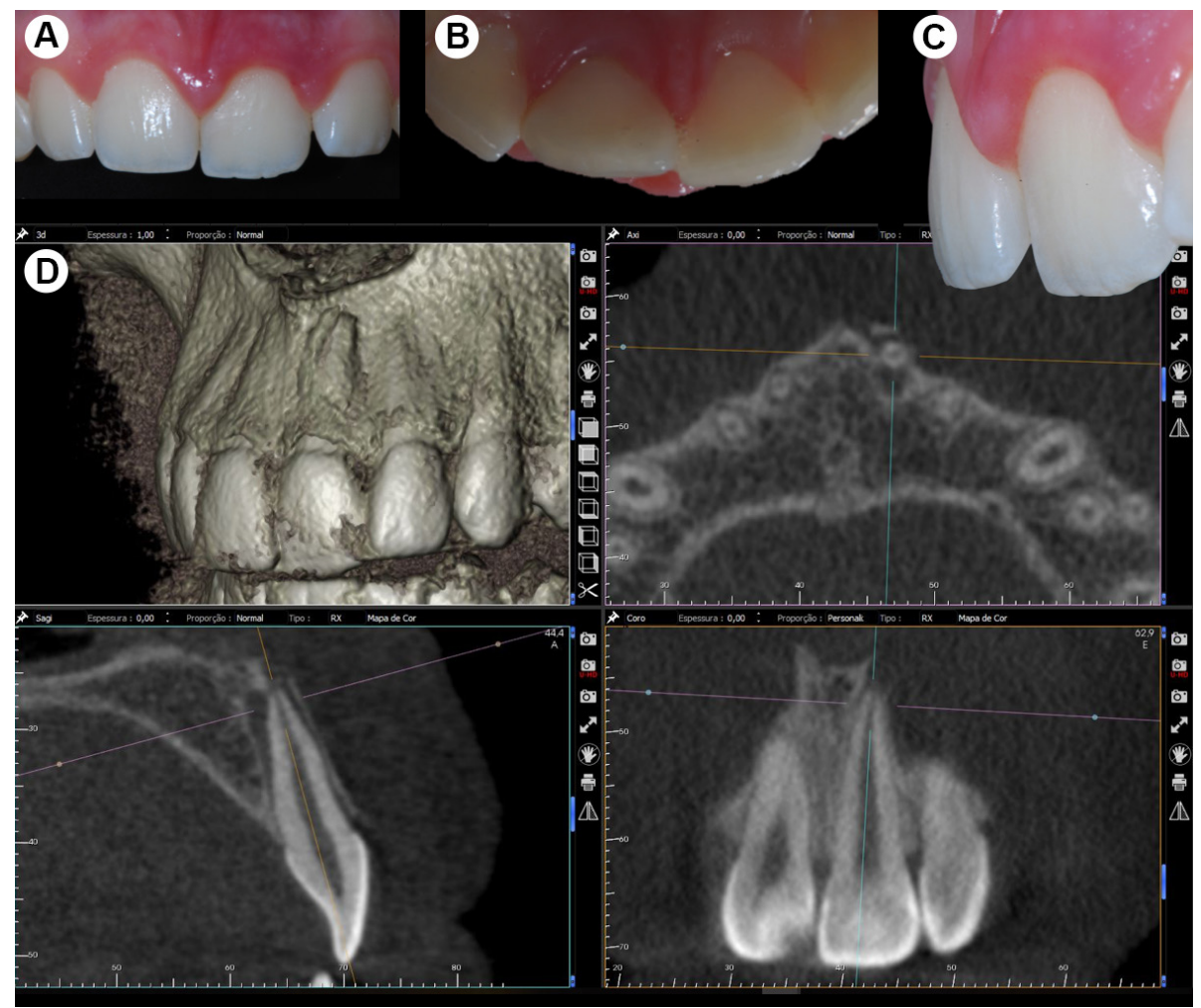

Figure 1. Initial aspect of the patient. A: frontal; B: incisal; C: and lateral view. It is possible to visualize an intumescence area in the cervical gingiva around in the upper left central incisor and the palatal position of the tooth; D: The 3D reconstruction of the initial aspect of the patient on e-Vol DX software and the sagittal, coronal and axial planes of the CBCT showing the fracture of the alveolar process and tooth displacement.
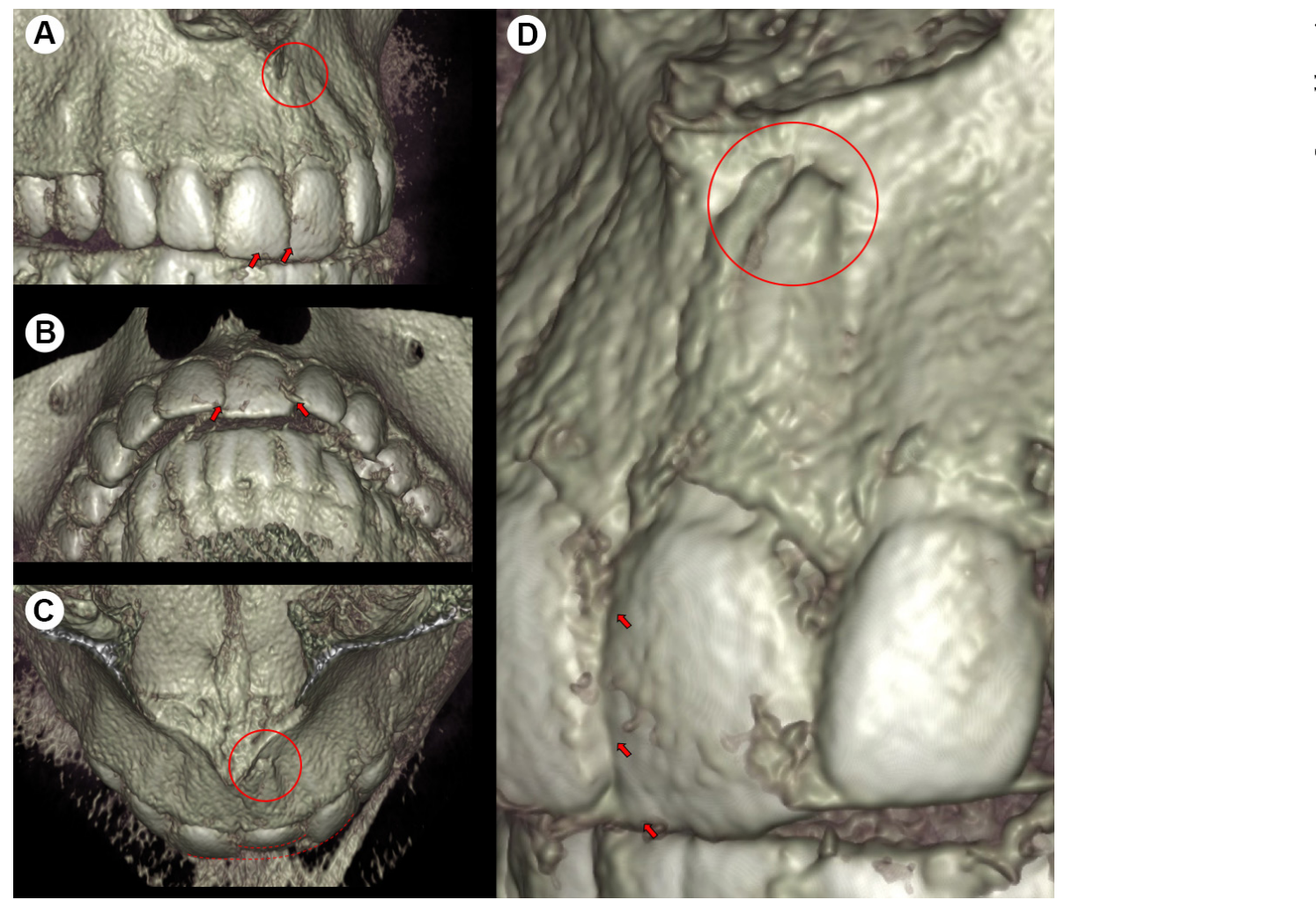

Figure 2. 3D reconstruction by using e-Vol DX software of the maxilla. A: The root apex of the upper left central incisor trapped outside the alveolus; B: Tooth displacement to the palatal position of an incisal view compared to the lateral incisor; C: Fracture of the alveolar process and the palatal position of the incisor on an upper view; D: Approximate view of the fracture of the buccal alveolar process. 
and radiograph examinations revealed normal outcomes with no evidence of root resorption and ankylosis.

\section{Discussion}

Lateral luxations on permanent teeth are one of the most prevalent injuries on dental trauma and the pulp necrosis is the most frequent complication, (3). however, if no treatment is undertaken, other complications as inflammatory resorption and chronic apical periodontitis can happen (4). The treatment is difficult because it involves many specialties as endodontic, periodontics and restorative dentistry. Additionally, complications may occur weeks, months or even years after the dental trauma, therefore, these injuries need long-term follow-ups $(1,4)$

The absence of correct diagnosis of an alveolar fracture can lead to incorrect treatment planning, resulting in complications and possible sequelae, mainly pulp necrosis and infection (6). Moreover, the incorrect repositioning of the tooth may lead to poor alveolar healing and chronic pain due to apical fenestration. The IADT guidelines recommend considering the need for СВCT based on the type and severity of the dentoalveolar injury (3). In this case report, CBCT imaging was important for treatment plan and helped CBCT scan of the upper maxilla of this patient resulted in an radiation of $57 \mu \mathrm{Sv}_{\text {, }}(13)$ medical CT scans of the upper maxilla result in an radiation of $1400 \mu S v(14)$. Even the full-mouth series radiographs, which is very common on the clinician daily basis, results in an radiation from 33-84 $\mu \mathrm{Sv}_{\text {, }}$

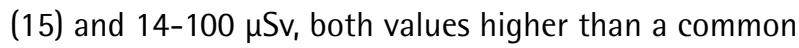
the CBCT scan (16) depending upon variables such as film speed, technique, $k V p$, and collimation.

CBCT technology should also be considered for followup examinations. Often, clinical examination and 2D radiographic imaging may not be sufficient to determine the presence or absence of pulp and periodontium healing. In such cases, the use of CBCT may provide the necessary evidence leading to a definitive diagnosis and treatment, if needed (6). Previous case reports have shown that occlusal or periapical radiography is an important tool to diagnose dental trauma $(17,18)$. However, presently, CBCT became more accessible, as a viable alternative for diagnose due to several cuts in different planes, which is important to highlight the root apex condition associated with lateral luxation. CBCT scanning is recognized to have higher accuracy and better resolution than radiography (19). In addition, radiographic exam is a two-dimensional view from a three-dimensional structure (6). The e-Vol DX facilitated the analysis and visualization of CBCT images. The use of specific filters was able to reconstruct and visualize the root apex and later the adequate bone healing. The application of this new software helped the diagnosis, planning and follow-up of the lateral luxation clinical case. The perspective of this new software for treatment of various complex dental trauma cases is potentially important.

Although the radiation doses of a CBCT scan is considered higher than a radiographic exam, it is justified for clinical cases where conventional radiographs cannot provide sufficient information (20). The CBCT exam associated with digitally reconstruction in this case report was important to define the correct diagnosis and consequently to establish the adequate treatment plan. The identification of the tooth apex positioning locked in buccal alveolar fracture, the distance of the tooth to its socket and furthermore to confirm the right repositioning were possible only after $\mathrm{CBCT}$ and digitally reconstruction exams. Additionally, the CBCT and mainly the e-Vol DX reconstruction contributed with better analysis of the possible signs of the initial root resorption, and to confirm the healing process of the alveolar process and correct endodontic treatment.

Since the alveolar bone fracture was presented, the rigid $0.7 \mathrm{~mm}$ stainless steel splint was used for 4 weeks, following the IADT recommendation (3). After that period, the rigid splint was changed for a semi-rigid splint using $1.0 \mathrm{~mm}$ of nylon thread and composite resin, which was maintained for other 2 weeks. This approach aimed to create the possibility of the more stable condition for bone healing (3). The replacement of stainless steel wire by nylon thread was done to optimize the physiological mobility due to its low stiffness (21)

Although the time elapsed between the dental trauma and the repositioning was not the ideal, digital repositioning to return the tooth back to the right position was considered correct, as it resulted in no periodontal sequelae. When the repositioning is incorrect or time elapsed is too long, the most common complications are pulp necrosis, root resorption, infection-related resorption, ankylosis and marginal bone loss (4). No large root resorption occurred, which might be explained due to the correct repositioning and the adequate treatment performed after short period $(10,22)$. The splinting time after lateral luxation injuries is considered important to maintain the traumatized tooth in right position, facilitating the bone alveolar process and periodontal ligament healing (3)

The patient complained of discomfort only on eating, which is common in lateral luxation injuries (23). Usually, lateral luxation is associated with injuries such as enameldentin fractures or soft tissue lacerations $(2,22)$, which were not observed in the present case report. Although it is considered a severe trauma, it was underestimated 

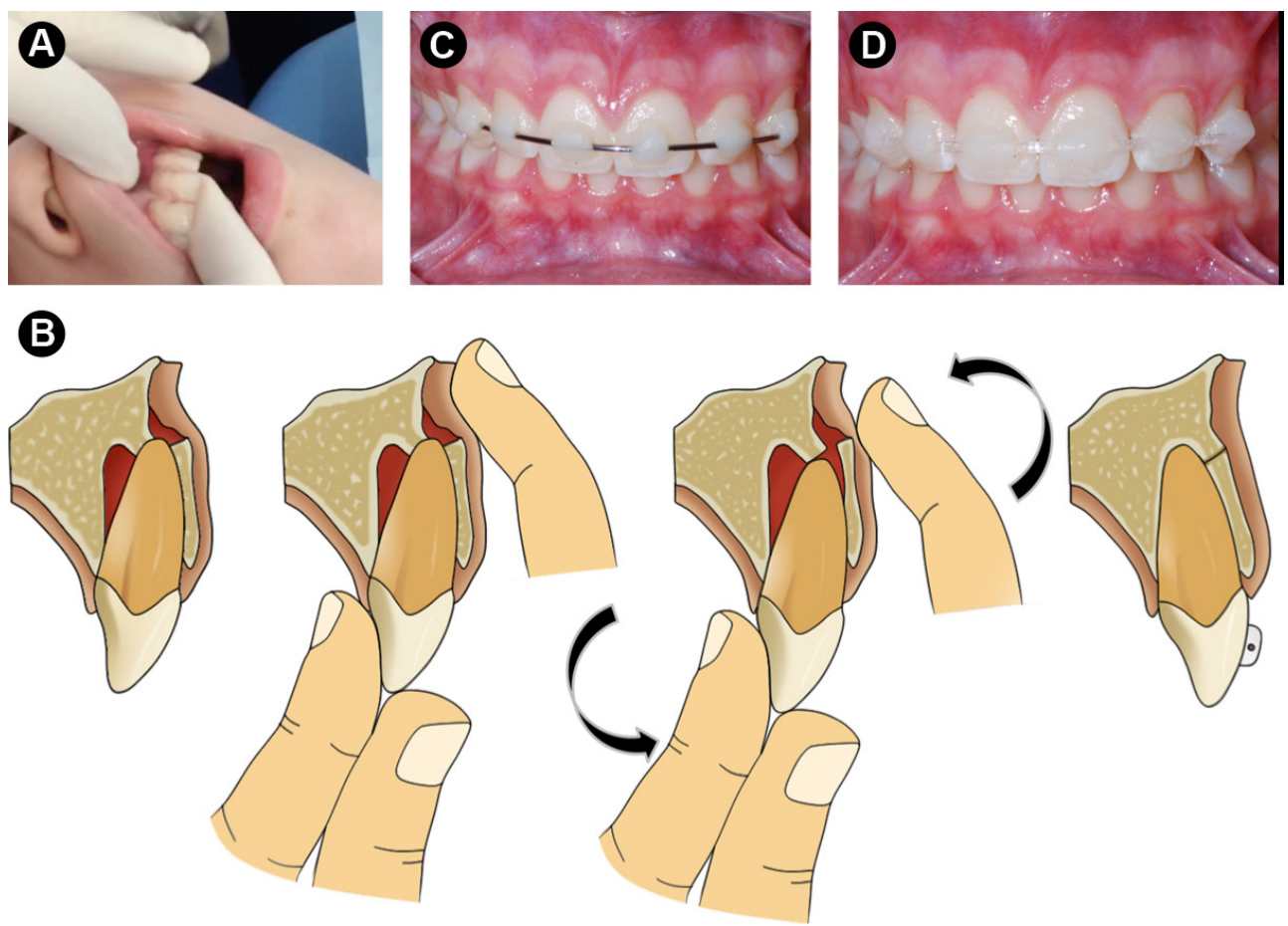

Figure 3. A: Emergency repositioning procedure of the maxillary left central incisor; B: Guideline image sequence showing the correct procedure to reposition a luxated tooth into its dental socket, reducing the buccal fracture of the alveolar process; C: Rigid splint with 0.7 mm orthodontic wire; D: semi-rigid splint with 1-mm nylon thread and composite resin.

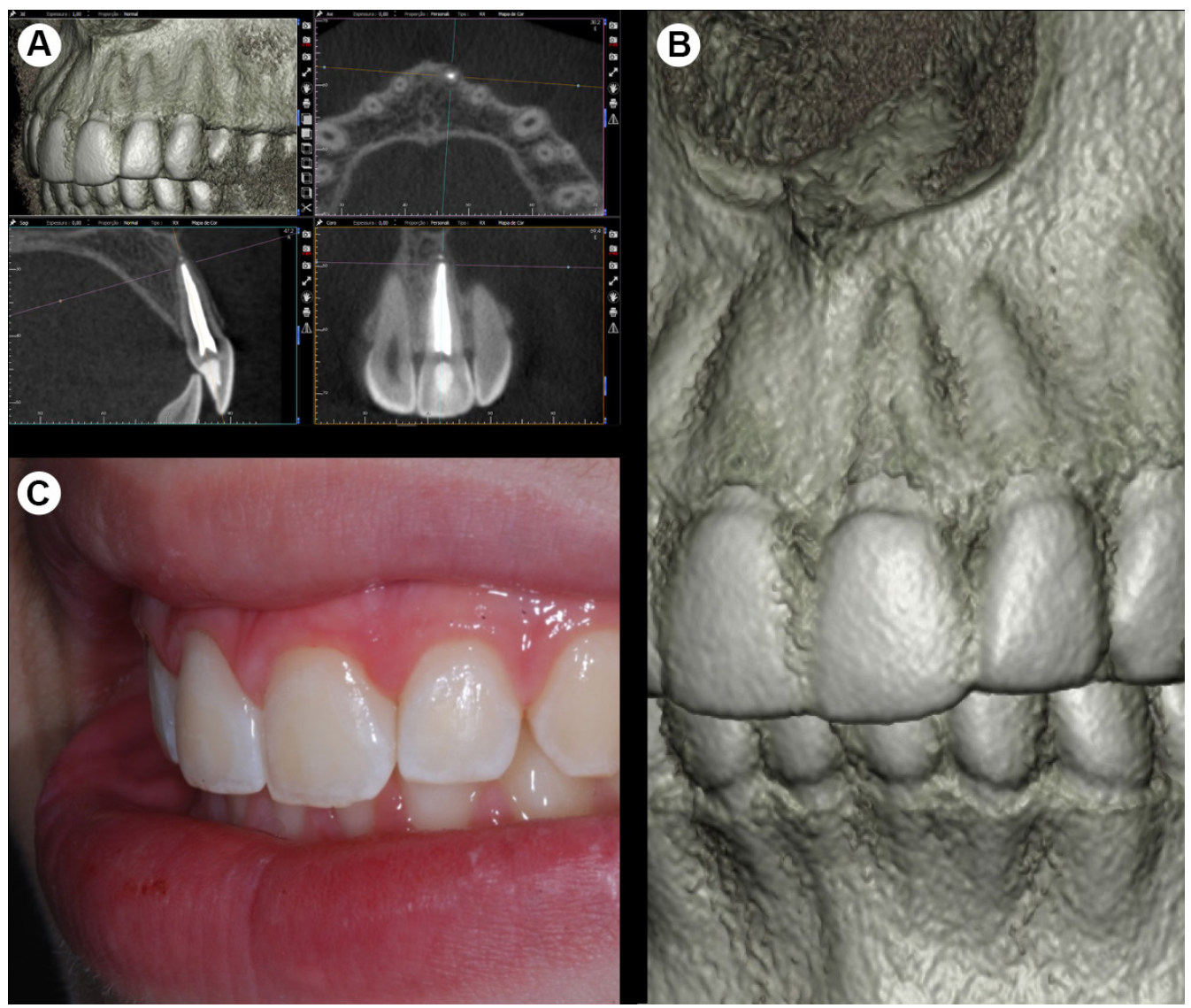

Figure 4. A: CBCT images and 3D reconstruction by using e-Vol DX software of the aspect of the patient, after 30 days, on the sagittal, coronal and axial planes; B: Close view of the 3D reconstruction showing bone healing at the site of the fracture of the alveolar process without any sign of complications; C: Final aspect of the patient with the tooth back to its physiological position and presenting good aesthetic harmony after 4 years. 
during the first exam due to the absence of concomitant dental fracture, mobility or laceration of the soft tissues.

The time elapsed between the trauma and the correct diagnosis of lateral luxation can be determinant for the treatment prognosis (7). Delayed repositioning is difficult if a clot is formed at ending of the dental socket (24), which was a concern in this particular case, but the clot did not prevent tooth repositioning. Continued exams are important due the possibility of later complications after the treatment (25). Follow-up of this case at 6 months, 1 , 2,3 and 4 years after an integrated and efficient treatment protocol showed an excellent outcome and satisfaction of the patient and his parents.

Lateral luxation is a serious dental trauma that involves the periodontal complex and alveolar bone. However, a multidisciplinary approach and a correct management of the case, as reported hereby, leads to a successful resolution.

This clinical case demonstrated the importance of $\mathrm{CBCT}$ and digital reconstruction using e-Vol DX software for a conclusive diagnosis and an adequate treatment planning of a lateral luxation dental trauma with 4 years of follow-up.

\section{Resumo}

Lesões de luxação lateral são uma das lesões periodontais mais graves no traumatismo dental. 0 diagnóstico seguido do reposicionamento do dente na posição correta é fundamental para o reparo do ligamento periodontal. Este estudo relata um caso clínico de luxação lateral do incisivo central superior envolvendo um novo software de reconstrução (e-Vol DX) por tomografia computadorizada de feixe cônico (TCFC) para confirmar a luxação lateral após nenhuma definição de lesão por trauma dental conclusivo pelo exame convencional. A lesão de luxação lateral foi reduzida digitalmente pela inserção do dente de volta ao seu alvéolo e, na mesma sessão, o dente foi estabilizado com uma contenção rígida e posteriormente trocada para uma contenção de nylon semirrigida. Durante o monitoramento da condição pulpar, foi diagnosticada necrose da polpa e, em seguida, o canal radicular foi tratado para evitar a reabsorção radicular. Procedimento externo de clareamento e restauração foi realizado. 0 acompanhamento de 4 anos e o novo exame de imagem e reconstrução digital não confirmaram reparo ósseo e nenhuma complicação. Imagens de TCFC analisadas pelo e-Vol DX podem ser utilizadas para determinar e orientar lesão de luxação lateral.

\section{Acknowledgments}

This study was supported by grants from CAPES-Finance code 001. This study was carried out at the Dental Trauma Service, Dental Hospital, School of Dentistry, Federal University of Uberlândia, MG, Brazil. The authors thank Gabriel Felipe de Bragança for preparing the schematic guideline images of Figure 3.

\section{References}

1. Mahmoodi B, Rahimi-Nedjat R, Weusmann J, Azaripour A, Walter C, Willershausen B. Traumatic dental injuries in a university hospital: a four-year retrospective study. BMC Oral Health 2015;15:139.

2. Lauridsen E, Hermann NV, Gerds TA, Ahrensburg SS, Kreiborg $\mathrm{S}$, Andreasen J0. Combination injuries 3. The risk of pulp necrosis in permanent teeth with extrusion or lateral luxation and concomitant crown fractures without pulp exposure. Dent Traumatol 2012;28:379-385.

3. Diangelis AJ, Andreasen JO, Ebeleseder KA, Kenny DJ, Trope $M$, Sigurdsson $A$, et al. International Association of Dental Traumatology. International Association of Dental Traumatology guidelines for the management of traumatic dental injuries: 1. Fractures and luxations of permanent teeth. Dent Traumatol 2012;28:2-12.

4. Hermann NV, Lauridsen E, Ahrensburg SS, Gerds TA, Andreasen JO. Periodontal healing complications following extrusive and lateral luxation in the permanent dentition: a longitudinal cohort study. Dent Traumatol 2012;28:394-402.

5. Lima TFR, Silva EJNLD, Gomes BPFA, Almeida JFA, Zaia AA, Soares AJ. Relationship between initial attendance after dental trauma and development of external inflammatory root resorption. Braz Dent J 2017;28:201-205.

6. Cohenca N, Silberman A. Contemporary imaging for the diagnosis and treatment of traumatic dental injuries: A review. Dent Traumatol 2017;33:321-328.

7. Cohenca N, Simon JH, Roges R, Morag Y, Malfaz JM. Clinical indications for digital imaging in dento-alveolar trauma. Part 1 : traumatic injuries. Dent Traumatol 2007;23:95-104.

8. American Association of Endodontists; American Acadamey of Oral and Maxillofacial Radiography. AAE and AAOMR joint position statement. Use of cone-beam-computed tomography in endodontics. Pa Dent J 2011;78:37-39.

9. Estrela C, Couto GS, Bueno MR, Bueno KG, Estrela LRA, Porto OCL, et al. Apical foramen position in relation to proximal root surfaces of human permanent teeth determined by using a new cone-beam computed tomographic software. J Endod 2018;44:1741-1748.

10. American Academy on Pediatric Dentistry Council on Clinical Affairs. Guideline on management of acute dental trauma. Pediatr Dent 2012-2013;36:230-238.

11. Zhu Y, Chen $H$, Cen L, Wang J. Influence of abutment tooth position and adhesive point dimension on the rigidity of a dental trauma wire-composite splint. Dent Traumatol 2016;32:225-230.

12. Lauridsen $E$, Gerds $T$, Andreasen JO. Alveolar process fractures in the permanent dentition. Part 2. The risk of healing complications in teeth involved in an alveolar process fracture. Dent Traumatol 2016;32:128-139.

13. Ludlow JB, Davies-Ludlow LE, Brooks SL. Dosimetry of two extraoral direct digital imaging devices: NewTom cone beam CT and Orthophos Plus DS panoramic unit. Dentomaxillofac Radiol 2003;32:229-234.

14. Ngan DC, Kharbanda OP, Geenty JP, Darendeliler MA. Comparison of radiation levels from computed tomography and conventional dental radiographs. Aust Orthod J 2003;19:67-75.

15. Danforth RA, Clark DE. Effective dose from radiation absorbed during a panoramic examination with a new generation machine. Oral Surg Oral Med Oral Pathol Oral Radiol Endod 2000;89:236-243.

16. Gibbs SJ. Effective dose equivalent and effective dose: comparison for common projections in oral and maxillofacial radiology. Oral Surg Oral Med Oral Pathol Oral Radiol Endod 2000;90:538-545.

17. Cunha RF, Delbem AC, de Mello Vieira AE, Pugliesi DM. Treatment of a severe dental lateral luxation associated with extrusion in an 8-month-old baby: a conservative approach. Dent Traumatol 2005;21:54-56.

18. Bechor R, Zadik Y. An unusual lateral luxation of an upper incisor owing to long-term boxing without protection. Dent Traumatol 2008;24:550-552.

19. Kim DM, Bassir SH. When Iscone-beam computed tomography imaging appropriate for diagnostic inquiry in the management of inflammatory periodontitis? An American Academy of Periodontology Best Evidence Review. J Periodontol 2017;88:978998.

20. Nikolic-Jakoba N, Spin-Neto R, Wenzel A. Cone-beam computed tomography for detection of intrabony and furcation defects: $A$ Systematic Review Based on a Hierarchical Model for Diagnostic 
Efficacy. J Periodontol 2016:87:630-644.

21. Ben Hassan MW, Andersson L, Lucas PW. Stiffness characteristics of splints for fixation of traumatized teeth. Dent Traumatol 2016;32:140-145.

22. De Rossi M, De Rossi A, Queiroz AM, Nelson Filho P. Management of a complex dentoalveolar trauma: a case report. Braz Dent J 2009;20:259-262.

23. Andreasen JO, Andreasen FM, Skeie A, Hjørting-Hansen E, Schwartz 0 . Effect of treatment delay upon pulp and periodontal healing of traumatic dental injuries -- a review article. Dent Traumatol 2002;18:116-128.
24. Hamanaka EF, Nogueira LM, Pires WR, Panzarini SR, Poi WR, Sonoda CK. Replantation as treatment for extrusive luxation. Braz Dent J 2015;26:308-311.

25. Heithersay GS. Life cycles of traumatized teeth: long-term observations from a cohort of dental trauma victims. Aust Dent J 2016;61:120-127.

Received September 20, 2019 Accepted December 11, 2019 